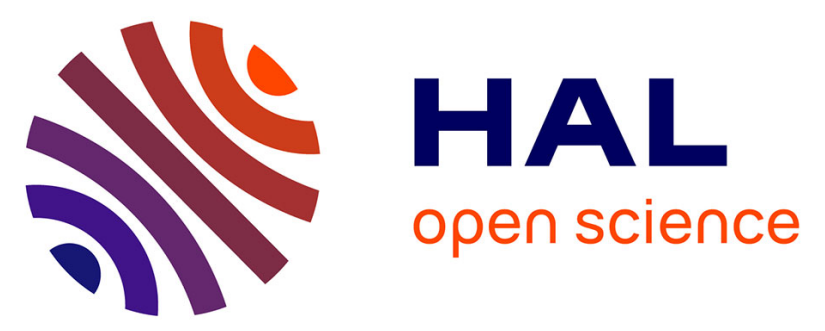

\title{
VEGF-A plasma levels are associated with microvascular obstruction in patients with ST-segment elevation myocardial infarction
}

\author{
Rodrigue Garcia, Claire Bouleti, Marc Sirol, Damien Logeart, Catherine \\ Monnot, Corinne Ardidie-Robouant, Giuseppina Caligiuri, Jean-Jacques \\ Mercadier, Stéphane Germain
}

\section{To cite this version:}

Rodrigue Garcia, Claire Bouleti, Marc Sirol, Damien Logeart, Catherine Monnot, et al.. VEGFA plasma levels are associated with microvascular obstruction in patients with ST-segment elevation myocardial infarction. International Journal of Cardiology, 2019, 291, pp.19 - 24. 10.1016/j.ijcard.2019.02.067 . hal-03486923

\section{HAL Id: hal-03486923 \\ https://hal.science/hal-03486923}

Submitted on 20 Dec 2021

HAL is a multi-disciplinary open access archive for the deposit and dissemination of scientific research documents, whether they are published or not. The documents may come from teaching and research institutions in France or abroad, or from public or private research centers.
L'archive ouverte pluridisciplinaire HAL, est destinée au dépôt et à la diffusion de documents scientifiques de niveau recherche, publiés ou non, émanant des établissements d'enseignement et de recherche français ou étrangers, des laboratoires publics ou privés.

\section{(ㅇ)(1) $\$$}

Distributed under a Creative Commons Attribution - NonCommerciall 4.0 International 


\title{
VEGF-A plasma levels are associated with microvascular obstruction in patients with ST-segment elevation myocardial infarction
}

\author{
Rodrigue GARCIA ${ }^{1,2^{*}}$, Claire BOULETI ${ }^{3 *}$, Marc SIROL ${ }^{4}$, Damien LOGEART ${ }^{5}$, Catherine \\ MONNOT $^{2}$, Corinne ARDIDIE-ROBOUANT ${ }^{2}$, Giuseppina CALIGIURI ${ }^{6 \$}$, Jean-Jacques \\ MERCADIER $^{7 \$}$, Stéphane GERMAIN ${ }^{2 \# \$}$ \\ * Both these authors contributed equally to this work \\ $\$$ These authors contributed equally to this work
}

${ }^{1} \mathrm{CHU}$ Poitiers, Service de Cardiologie, 2 rue de la Milétrie 86021 Poitiers, France. This author takes responsibility for all aspects of the reliability and freedom from bias of the data presented and their discussed interpretation

${ }^{2}$ Center for Interdisciplinary Research in Biology (CIRB), College de France - Centre National de la Recherche Scientifique (CNRS), Institut National de la Santé et de la Recherche Médicale (INSERM), Paris Sciences et Lettres (PSL) Research University, 11, place Marcelin Berthelot, Paris F-75005, France. This author takes responsibility for all aspects of the reliability and freedom from bias of the data presented and their discussed interpretation

${ }^{3}$ Hôpital Bichat, APHP, Cardiology department, 46 Rue Henri Huchard, 75877 Paris. This author takes responsibility for all aspects of the reliability and freedom from bias of the data presented and their discussed interpretation

${ }^{4}$ Hôpital Ambroise-Paré, 9 Avenue Charles de Gaulle, 92100 Boulogne-Billancourt; INSERM U1018, Team 5 Université Paris Sud-Université Versailles Saint Quentin en Yvelines, CESP (Centre for Epidemiology and Population Health EpReC Team, Renal and Cardiovascular Epidemiology). This author takes responsibility for all aspects of the reliability and freedom from bias of the data presented and their discussed interpretation ${ }^{5}$ Hopital Lariboisière, HEGP 2 rue Ambroise-Paré 75010 Paris. This author takes responsibility for all aspects of the reliability and freedom from bias of the data presented and their discussed interpretation ${ }^{6}$ INSERM U 1148, Paris F-75018, France; This author takes responsibility for all aspects of the reliability and freedom from bias of the data presented and their discussed interpretation

${ }^{7}$ Signalisation and Cardiovascular Pathophysiology - UMR-S 1180, Univ. Paris-Sud, INSERM, Université ParisSaclay, 92296, Châtenay-Malabry, France. This author takes responsibility for all aspects of the reliability and freedom from bias of the data presented and their discussed interpretation

\# Corresponding author:

\section{Stéphane Germain}

Address: Collège de France, 11, place Marcelin Berthelot, Paris F-75005, France.

Tel: +33 144271664; Fax: +33 144271691;

Email address: stephane.germain@college-de-france.fr

Conflicts of interest: none

KEY WORDS: VEGF-A; myocardial infarction; microvascular obstruction; no-reflow phenomenon; magnetic resonance imaging 


\section{INTRODUCTION}

Despite successful opening of the culprit coronary vessel in patients undergoing percutaneous coronary intervention $(\mathrm{PCl})$, re-perfusion of the tributary myocardial tissue remains impaired due to the "no-reflow" phenomenon with microvascular obstruction (MVO) in about $50 \%$ of patients after STEMI ${ }^{1,2}$. Among the biologic processes taking place in impaired myocardial reperfusion, the compression of the cardiomyocytes by the local edema due to increased vascular permeability plays an important role: the alteration of tight and adherens junctions leads to vascular leakage with leukocyte infiltration, erythrocyte accumulation in the interstitium and further exacerbation of $\mathrm{MVO}^{3,4}$. Recognition of MVO is important because it carries a poor prognosis with a higher occurrence of heart failure and a 1.7 fold increased risk of death ${ }^{5}$.The detection of hypoenhancement zones on first-pass perfusion magnetic resonance imaging (MRI) represents the reference for non-invasive diagnosis ${ }^{6}$. However, MRI is not available in a number of centers and cannot be performed in patients with haemodynamic instability. Availability of a biomarker would dramatically help to broaden the diagnosis of MVO and improve the clinical management of patients with STEMI ${ }^{7}$.

Vascular endothelial growth factor-A (VEGF-A), which is actively produced in the damaged myocardium to foster angiogenesis and tissue repair, is a major effector of endothelial junction disruption and vascular leakage through activation of the Src Signaling pathway ${ }^{8,9}$. Plasma VEGF-A levels were recently identified as a possible biomarker of MVO in STEMI patients but given the limited power of the sample size, the results were not statistically significant ${ }^{10}$. 
The aim of this study was to assess whether plasma VEGF-A levels are associated with MVO diagnosed by MRI in patients with a first STEMI included in the CMR substudy of the PREGICA cohort. (https://clinicaltrials.gov/ct2/show/NCT01113268). 


\section{METHODS}

\subsection{Patients}

The PREGICA study (ClinicalTrials. gov identifier: NCT01113268) involved 6 French centers. All consecutive patients between 18 and 80 years old referred for a first STEMI between September 2010 and December 2017 were screened for eligibility. STEMI was defined by the presence of i) electrocardiogram ST-segment elevation or Q-wave in at least 2 contiguous leads; ii) significant rise of troponin $\geq 3$-fold higher than the upper limit reference; iii) > 2 myocardial akinetic segments at trans-thoracic echocardiography carried out at day $4 \pm 2$ after hospital admission, which was the inclusion day. Patients were not included if they had permanent atrial fibrillation, or history of valvular, hypertrophic or dilated cardiomyopathy, cardiac surgery, anthracycline treatment or any contra-indications to MRI (claustrophobia, severe renal failure defined as creatinin levels $>1.5 \mathrm{mg} / \mathrm{dl}$, cardiogenic shock or hemodynamic instability, non-retrievable metallic implants). As part of the protocol, cardiac MRI was systematically performed if available at day $4 \pm 2$ days and at 6 -month follow-up. The patients who underwent cardiac MRI constitute the population of the CMR substudy of the PREGICA cohort, as previously reported ${ }^{11}$. Blood samples were drawn the same time, for VEGF-A measurements. In order to avoid cofounder pathophysiology such as myocardial infarction with non-obstructive coronary arteries, we excluded patients with a pre-PCI TIMI flow $\geq 2$ on their initial coronary angiogram. The study was conducted according to the ethical principles stated in the Declaration of Helsinki and approved by local ethics committees. Written informed consent was obtained from all subjects. 


\subsection{Cardiac Magnetic Resonance Imaging}

Cardiac MRI was performed using a $1.5-T$ unit at day $4 \pm 2$ after hospital admission and at 6month follow-up in all patients of the CMR substudy $(n=185)$. All studies were performed using dedicated cardiac software, phased-array surface receiver coil, and electrocardiogram triggering, as previously described ${ }^{12}$. A standardized MRI protocol was followed in all centers. Cine images were acquired using a breath-hold steady-state free-precession sequence in long-axis and short-axis views. A stack of short-axis slices covering from the atrioventricular ring to the apex was used to derive left ventricular (LV) volumes, and ejection fraction (EF). Ten minutes after intravenous injection of gadolinium-based contrast agent, late gadolinium enhancement (LGE) images were acquired using a breath-hold segmented T1-weighted inversion-recovery gradient-echo sequence in the same long-axis and short-axis views of cine images. Inversion time was individually optimized to null normal myocardium. LGE images were assessed for infarct size and MVO.

All images were anonymized, stored in DICOM format, and centrally analyzed in a core lab at the Ambroise Paré University Hospital, Boulogne Billancourt, France, using vendor independent software (Qmass MR 7.0; Medis, Leiden, the Netherlands) by consensus of 2 experienced operators blinded of clinical data. The mass of infarcted myocardium was quantified on LGE images using the full width at half maximum (FWHM) technique, which uses half the maximal signal within the scar as the threshold. MVO was defined as a subendocardial hypo-enhanced region within the infarcted myocardium. Quantitative MVO size was determined on short axis images by manual tracing on LGE images, and expressed as a percentage of infarct size, as previously described ${ }^{13}$. 


\subsection{Laboratory assays}

Peripheral blood samples were drawn at inclusion (day $4 \pm 2$ ) for all patients, the same day as cardiac MRI was performed. Aliquots were stored at $-80^{\circ} \mathrm{C}$ until assayed. On the day of the biomarker analysis, EDTA plasma samples were thawed, centrifuged at $16000 \mathrm{~g}$ to get rid of cryoaggregates and macroparticules, and the supernatant was used for analysis, diluted 1:4 in saline buffer. Concentrations of VEGF-A were determined using immunodetection beadbased (Luminex ${ }^{\circledR}$ ) technology (Bio-Plex Pro Human Cancer2 VEGF-A Set, Bio-Rad reagent), following the manufacturer's instructions (the detailed protocol is described in Supplementary Material 1). C-reactive protein and Troponin T serum levels were measured every $6 \mathrm{~h}$ during the first day and once a day during the following 4 days, using standardized methods, in each center participating in the PREGICA study.

\subsection{STEMI management}

All patients were treated by primary percutaneous coronary intervention ( $\mathrm{PCl})$ in accordance with the consensus guidelines ${ }^{14}$.Coronary flow in the culprit artery before and after revascularization by $\mathrm{PCl}$ was graded according to the TIMI study group classification ${ }^{15}$. . All patients underwent a dedicated 2D echocardiography in order to determine the number of akinetic segments at day $4 \pm 2$. The use of appropriate antithrombotic and heart failure therapy was left to the discretion of the cardiologists in charge.

\subsection{Statistical analysis}

Categorical variables were expressed as numbers and percentages, continuous variables as mean \pm standard deviation or median $\left(25-75^{\circ}\right.$ percentiles). Comparisons between groups were performed using chi-square for categorical variables and student $t$ test or MannWhitney test as appropriate for quantitative variables. The analysis of the factors associated 
with MVO was initially evaluated in univariable analysis. Multivariable logistic regression was used to assess whether VEGF was independently associated with MVO. The variables with $p<0.10$ in univariable analysis were included in the multivariable model with a backward logistic regression analysis with a threshold of $p=0.05$. Correlations were assessed using Pearson or Spearman correlation coefficient, as appropriate.

Analyses were performed using SPSS 22 (SPSS, Inc., Chicago, IL, USA). Two-sided P values $<0.05$ were considered statistically significant. 


\section{RESULTS}

\subsection{Microvascular obstruction in patients with pre-PCI TIMI flow 0-1}

In the PREGICA study, 929 consecutive patients were prospectively included, among whom 185 underwent a cardiac MRI and form the population of the CMR substudy. (Figure 1). Baseline characteristics of the 147 included patients are illustrated in Table 1. Mean age was $57 \pm 10$ years and 124 patients were male (84\%). The mean time between patient symptoms and $\mathrm{PCl}$ was $4.9 \pm 4.7$ hours and the maximal delay between chest pain onset and $\mathrm{PCl}$ was 9.6 hours. The culprit coronary vessel was the left anterior descending artery in 94 (64\%) patients, the right coronary artery in $33(22 \%)$ patients and the circumflex artery in $20(14 \%)$ patients. MVO as assessed by systematic cardiac MRI at day $4 \pm 2$, was present in 65 (44\%) patients. All patients with MVO exhibited a transmural infarction as assessed by contrast enhancement, whereas $73 \%$ exhibited this feature in patients without MVO $(p<0.001)$. VEGF-A serum levels were significantly higher in patients with MVO as compared to patients without MVO: $250 \pm 211$ vs. $191 \pm 119 \mathrm{pg} / \mathrm{mL} ; \mathrm{p}=0.03$. The mean delay to VEGF measurement was $3.8 \pm 1.1$ days without significant correlation between time to VEGF analysis and VEGF concentration ( $R=0.007 ; p=0.93)$.

T-Troponin peak and C-reactive protein levels at day 4 were significantly higher in patients with MVO as compared to patients without MVO: $141 \pm 139 \mu \mathrm{g} / \mathrm{L}$ vs. $86 \pm 112 \mu \mathrm{g} / \mathrm{L} ; \mathrm{P}=0.009$ and $38 \pm 48 \mathrm{mg} / \mathrm{L}$ vs. $22 \pm 29 \mathrm{mg} / \mathrm{L} ; \mathrm{p}=0.02$, respectively. Patients with MVO more frequently had a history of hypertension as compared to patients without MVO $(p=0.03)$, while there was no difference between groups regarding the other cardiovascular risk factors. 
The following variables with a $p<0.10$ in univariable analysis were included in the multivariable analysis: hypertension, transmurality of the infarction, troponin, C-reactive protein and VEGF-A levels. According to the results, only 2 independent factors were associated with MVO as assessed by cardiac MRI:

i) higher troponin levels with OR 1.005 with 95\% confidence interval (CI) (1.002-1.009) per $\mu g / L$ increase; $p=0.003$.

ii) higher VEGF-A serum levels with OR 1.003; 95\% Cl (1.001-1.005) per pg/ml increase; $p=$ 0.012 .

The median extent of MVO (expressed as the percent of left ventricular myocardial mass) was $2.16 \%$ IQR (0.0-6.5). There was no significant correlation between delay to MRI and extent of MVO ( $r=0.12 ; p=0.16)$. There was a significant positive correlation between MVO and infarct size $(r=0.60, p<0.001)$, as well as between MVO size and VEGF levels $(r=0.20$, $p=0.018)$ and a negative correlation between MVO size and LVEF $(r=-0.33 ; p<0.001)$ No pretreatment was significantly associated with MVO, but patients under statin therapy did exhibit lower VEGF levels as compared with patients free of statin: median VEGF levels 114 (84-196) pg/ml versus 196 (103-291) pg/ml; p=0.04. To analyze whether VEGF levels remained significantly associated with MVO, independently of statin treatment, we performed a second multivariable analysis with the variable "statin therapy" forced in the model. The results were unchanged with this second model and only higher troponin levels and higher VEGF-A serum levels remained significantly associated with MVO (Supplementary Material 2). The combination of VEGF levels and troponin peak led to an area under the curve for MVO diagnosis of 0.68 . 


\subsection{Microvascular obstruction in patients with post-PCI TIMI flow 3}

Among the 147 patients analyzed at first step, 17 patients (12\%) had a final TIMI flow $<3$ despite $\mathrm{PCl}$, including 1 patient with TIMI flow 0, 6 with TIMI flow 1 and 10 with TIMI flow 2. VEGF-A levels were statistically higher in the 17 patients with post-PCI TIMI flow $<3$ as compared to patients with successful PCl, defined as a final TIMI flow of 3: median 235 (83483) $\mathrm{pg} / \mathrm{ml}$ and 187 (103-263) pg/ml respectively, $\mathrm{p}=0.03$, as illustrated in Supplementary Material 3. The characteristics of these 17 patients with angiographic NR as compared to patients with good results of $\mathrm{PCl}$ are presented in Supplementary Material 4.

To make sure that the higher VEGF-A levels found in patients with MRI-diagnosed MVO were not due to these 17 patients with suboptimal results of $\mathrm{PCl}$, they were excluded and the analysis was performed on the 130 patients with a successful $\mathrm{PCl}$.

Among the 130 patients with final TIMI flow 3, 56 patients (43\%) had MVO diagnosed by MRI. The characteristics of these patients are presented according to the presence or absence of MRI-diagnosed MVO in Supplementary Material 5. In line with the previous results, higher VEGF-A levels as well as increased troponin and C-reactive protein levels were found in patients with MVO as compared to patients without MVO. Patients with MVO also more frequently had high blood pressure as compared to patients without MVO. These 4 variables with $p<0.10$ were consequently included in the multivariable analysis. We found 2 factors to be independently associated with MVO: i) higher troponin levels OR $1.00695 \% \mathrm{Cl}(1.002-$ 1.009); $p=0.004$ and ii) higher VEGF-A levels OR $1.00395 \% \mathrm{Cl}(1.000-1.006) ; p=0.03$. Taken together, these results show that higher VEGF-A levels are associated with MVO, diagnosed by coronary angiography (final TIMI flow $<3$ ) and by MRI only in patients who underwent successful PCI (final TIMI flow=3). 


\subsection{Immediate and 6-month follow-up deleterious consequences of MVO}

As previously reported, MVO was associated with significantly higher myocardial infarction size and lower LVEF. In the 130 patients with final TIMI flow= 3, the 56 patients with MVO had a mean infarct size, assessed by cardiac MRI at day 4 , of $47.3 \pm 17.2$ g versus $28.9 \pm 14.8$ $\mathrm{g}$ in patients without MVO, $\mathrm{p}<0.0001$. In line with these results, the number of akinetic segments, assessed by echocardiography at inclusion, was significantly higher in patients with MVO as compared to patients without MVO: $5.6 \pm 2.0$ versus $4.3 \pm 2.0$ segments respectively; $p=0.0003$. These 56 patients also exhibited significantly lower LVEF of $43.7 \pm$ $6.5 \%$ versus $47.0 \pm 7.0 \%$ in patients without $M V O, p=0.007$ (Figure 2 ).

Patients were once again evaluated at 6 months follow-up with cardiac MRI for LV remodeling assessment. The data were available for 53 of the 56 patients with MVO and 72 of the 74 patients without MVO at initial MRI examination. These 5 patients were missing because of loss for follow-up in 2 cases and refusal to undergo repeated cardiac MRI for 3 others. At 6-month examination, MVO had disappeared in all patients.

The presence of MVO diagnosed at admission was associated with adverse LV remodeling. Indeed, while there was no significant difference in indexed LV end-diastolic volumes (LVEDVi) between MVO and non-MVO patients at day 4, $\left(83.8 \pm 13.8 \mathrm{ml} / \mathrm{m}^{2}\right.$ versus $89 \pm 20$ $p=0.11$ ), patients with MVO exhibited significant increased LVEDVi at 6 months follow-up as compared to patients without MVO: $99.7 \pm 20.9 \mathrm{ml} / \mathrm{m}^{2}$ versus $89.6 \pm 27.7 \mathrm{ml} / \mathrm{m}^{2}, \mathrm{p}=0.03$. Moreover, compared to baseline, mean LVEDVi significantly increased at 6 months for the 53 patients with MVO: $83.8 \pm 13.8 \mathrm{ml} / \mathrm{m}^{2}$ at day 4 versus $99.7 \pm 20.9 \mathrm{ml} / \mathrm{m}^{2}$ at month 6 ; $p<0.0001$. On the other hand, patients without MVO had no LV remodeling over time with no significant change in LVEDVi: $89.1 \pm 20.5 \mathrm{ml} / \mathrm{m}^{2}$ at day 4 versus $89.6 \pm 27.7 \mathrm{ml} / \mathrm{m}^{2}$ at 
month $6, p=0.79$. The remodeling index, as defined by the ratio between LVEDV at month 6 and at day 4 was significantly increased in MVO patients as compared to patients without MVO: $1.2 \pm 0.2$ versus $1.0 \pm 0.2, p<0.0001$

In accordance with these results, LVEF as assessed by cardiac MRI at 6 months was significantly impaired in patients with MVO as compared to patients without MVO. Indeed, mean LVEF was $45.7 \pm 7.8 \%$ in MVO patients as compared to $50.8 \pm 9.0 \%, p=0.001$ (Figure 3 ). Finally VEGF-A levels were inversely correlated with LVEF, with a non-significant trend at baseline $(p=0.12)$ but statistically significant at 6-month follow-up $(R=-0.21, p=0.017)$ (Supplementary Material 6). This correlation remained significant after adjustment for statin therapy, neurohormonal blockade treatments and beta-blockers. 


\section{DISCUSSION}

In the present study, we assessed the association between VEGF-A levels and MVO after a first STEMI. We found that VEGF levels were associated with MVO both in patients with angiographic no-reflow (post-PCI TIMI flow < 3) and in patients with successful PCI (final TIMI flow $\geq 3$ ). Moreover, after successful recanalization, only increased VEGF-A and troponin levels were independently associated with the presence of MVO in multivariable analysis. High VEGF-A level was associated with impaired LVEF at 6 months.

\subsection{VEGF is independently associated with MVO}

VEGF-A is expressed in response to hypoxia during acute myocardial infarction ${ }^{8,9,16,17}$. Its beneficial pro-angiogenic effect in the ischemic myocardium has been demonstrated ${ }^{18,19}$. VEGF-A was therefore the first candidate for therapeutic trials in ischemic myocardial diseases but with disappointing results in randomized controlled trials ${ }^{20,21}$. Focusing only on the pro-angiogenic role of VEGF-A seems to be a limitation of the multiple functions of this factor. Indeed, VEGF-A also has pro-inflammatory properties and is an important inductor of vascular permeability ${ }^{22}$. Pannitteri et al. showed that VEGF-A has a 2-peak release during MI in humans and, while the second peak may support the pro-angiogenic effects, the first peak is likely to be responsible for vascular leakage ${ }^{8}$. At the acute phase of ischemic injury, VEGFA increases permeability in infarcted tissues ${ }^{23-25}$. Myocardial edema contributes to vessel collapse, reperfusion arrhythmias and stunning, and may also be involved in adverse ventricular remodeling through changes in myocardial stiffness ${ }^{20}$. All of these mechanisms could be responsible for extended tissue lesions and increased infarct size. Blockade of the VEGF-A pathway in preclinical models of MI has led to decreased infarct size and improved 
outcome $^{23}$. Cerebral ischemia shares common pathophysiology with MI and promising results have been reported when inhibiting or counteracting VEGF-A pathway after ischemic stroke $^{26,27}$. However, none of these trials were performed in humans. Another study on 50 consecutive $\mathrm{MI}$ patients reported that decreased VEGF levels by statin therapy were associated with improvement of LVEF through counteraction of its pro-inflammatory properties $^{28}$.

In the present study, we have shown an association between increased VEGF-A levels and MVO as diagnosed by cardiac MRI, the reference method, at day $4 \pm 2$. The peak of circulating VEGF levels was reached between day 1 and day 14 in most studies ${ }^{8,9,17}$. In the detailed study by Panniterri et al, the first peak was established at day $1-2^{8}$. Due to cardiac MRI constraints and limited availability in the setting of emergency, it was not possible in this study to assess at the same time MVO and VEGF levels at day 1-2. Here, he measurements were performed at day $4 \pm 2$, according to the predefined protocol. VEGF-A levels were significantly increased in patients with angiographic NR as compared to patients with final coronary TIMI 3 flow, and were also significantly and independently associated with MVO in the 130 patients with successful $\mathrm{PCl}$. Counteracting or inhibiting the early VEGF-A peak at the acute phase of $\mathrm{MI}$ in humans could therefore be of interest to limit MVO and its deleterious consequences. These results are provocative as they seem diametrically opposed to previous thinking on the role of VEGF-A during acute $\mathrm{MI}$ in humans. Larger trials are needed to confirm these results but this study opens new perspectives of research for MVO prevention and treatment.

\subsection{MVO and VEGF levels are associated with LVEF at 6-month follow-up}


The prevention of $\mathrm{LV}$ adverse remodeling after acute $\mathrm{MI}$ is one of the most important challenges for clinicians given its association with heart failure and its inherent morbimortality ${ }^{29}$. Cardiac MRI is the gold standard non-invasive technique for assessment of $\mathrm{LV}$ remodeling ${ }^{30}$. In our STEMI cohort, we found an association between MVO and LV remodeling with a significant increase in LVEDVi between baseline and 6-month follow-up in MVO patients, resulting in a significant decrease in LVEF.

In this study we report an association between VEGF-A levels at baseline and LVEF at 6month follow-up. Higher VEGF-A levels at admission in the study were indeed significantly correlated with impaired LV function at 6-month follow-up after STEMI ( $p=0.017)$.

The present findings suggest that it could be of importance to evaluate VEGF-A levels in clinical practice in order to identify patients at risk of MVO and to predict LVEF impairment at mid-term follow-up after STEMI. Moreover, therapies aimed at counteracting VEGF-A effect at the acute phase of STEMI could have beneficial effect by diminishing MVO and improving systolic function. Patients with high VEGF-A levels during STEMI could consequently benefit from closer follow-up and more aggressive titration of anti-remodeling and heart failure treatments.

\subsection{Limitations}

Some limitations of this study should be acknowledged. Firstly, as only patients with $\geq 3$ akinetic segments were included, our conclusions may not apply to patients with smaller MI. Secondly, in order to ensure the homogeneity of the population, we selected patients with an initial TIMI flow 0-1 of the culprit artery on admission. For this reason and due to the 
systematic use of myocardial MRI, our population may not be fully representative of all STEMI patients.. Thirdly, as most studies on STEMI patients, we report an important male predominance, thus limiting the generalization of results to female population, although gender did not seem to influence the present results. Finally, it may have been more appropriate to measure VEGF levels at day 1-2 or to have serial VEGF measurements. However, this proof of concept study is the first to highlight the potential deleterious role of VEGF during STEMI in humans. Larger studies with optimal sampling time points may allow for even better results in this setting.

\section{CONCLUSION}

This study demonstrated for the first time that VEGF-A levels after STEMI were associated with MVO as assessed by cardiac MRI, both in patients with angiographic NR and in patients with successful PCI. Moreover, VEGF-A levels were inversely correlated with LVEF at 6month follow-up. While further studies are needed to confirm our results, early measurement of VEFG-A could be of pronounced interest to stratify patient prognosis and to guide individualized follow-up and treatment. 


\section{ACKNOWLEDGMENTS}

We thank Jeffrey Arsham for correcting this manuscript. 


\section{REFERENCES}

1. van der Laan AM, Piek JJ and van Royen N. Targeting angiogenesis to restore the microcirculation after reperfused MI. Nat Rev Cardiol. 2009;6:515-23.

2. Bouleti C, Mewton N and Germain S. The no-reflow phenomenon: State of the art. Arch Cardiovasc Dis. 2015;108:661-74.

3. Murakami M and Simons M. Regulation of vascular integrity. J Mol Med (Berl). 2009;87:571-82.

4. Heusch G, Kleinbongard P, Skyschally A, Levkau B, Schulz R and Erbel R. The coronary circulation in cardioprotection: more than just one confounder. Cardiovasc Res.

5. Ndrepepa G, Tiroch K, Fusaro M, Keta D, Seyfarth M, Byrne RA, Pache J, Alger P, Mehilli J, Schomig A and Kastrati A. 5-year prognostic value of no-reflow phenomenon after percutaneous coronary intervention in patients with acute myocardial infarction. J Am Coll Cardiol. 2010;55:2383-9.

6. Albert TS, Kim RJ and Judd RM. Assessment of no-reflow regions using cardiac MRI. Basic Res Cardiol. 2006;101:383-90.

2012;94:237-45.

7. Garcia-Dorado D and Oliveras J. Myocardial oedema: a preventable cause of reperfusion injury? Cardiovasc Res. 1993;27:1555-63.

8. Pannitteri G, Petrucci E and Testa U. Coordinate release of angiogenic growth factors after acute myocardial infarction: evidence of a two-wave production. J Cardiovasc Med (Hagerstown). 2006; 7:872-9.

9. Kranz A, Rau C, Kochs M and Waltenberger J. Elevation of vascular endothelial growth factor-A serum levels following acute myocardial infarction. Evidence for its origin and functional significance. J Mol Cell Cardiol. 2000;32:65-72.

10. Bouleti C, Mathivet T, Serfaty JM, Vignolles N, Berland E, Monnot C, Cluzel P, Steg PG, Montalescot $\mathrm{G}$ and Germain S. Angiopoietin-like 4 serum levels on admission for acute myocardial infarction are associated with no-reflow. Int J Cardiol. 2015;187:511-6.

11. Gellen B, Biere L, Logeart D, Lairez O, Vicaut E, Furber A, Mercadier JJ and Sirol M. Timing of Cardiac Magnetic Resonance Imaging Impacts on the Detection Rate of Left Ventricular Thrombus After Myocardial Infarction. JACC Cardiovasc Imaging. 2017;10:14041405.

12. Sirol M, Gzara H, Gayat E, Dautry R, Gellen B, Logeart D, Soyer P, Vicaut E and Mercadier JJ. Comparison between visual grading and planimetric quantification of microvascular obstruction extent assessment in reperfused acute myocardial infarction. Eur Radiol. 2016;26:2166-75.

13. de Waha S, Patel MR, Granger CB, Ohman EM, Maehara A, Eitel I, Ben-Yehuda O, Jenkins $P$, Thiele $H$ and Stone GW. Relationship between microvascular obstruction and adverse events following primary percutaneous coronary intervention for ST-segment elevation myocardial infarction: an individual patient data pooled analysis from seven randomized trials. Eur Heart J. 2017;38:3502-3510.

14. Ibanez B, James S, Agewall S, Antunes MJ, Bucciarelli-Ducci C, Bueno H, Caforio ALP, Crea F, Goudevenos JA, Halvorsen S, Hindricks G, Kastrati A, Lenzen MJ, Prescott E, Roffi M, Valgimigli M, Varenhorst C, Vranckx P, Widimsky P and Group ESCSD. 2017 ESC Guidelines for the management of acute myocardial infarction in patients presenting with ST-segment elevation: The Task Force for the management of acute myocardial infarction in patients 
presenting with ST-segment elevation of the European Society of Cardiology (ESC). Eur Heart J. 2018;39:119-177.

15. Group TS. The Thrombolysis in Myocardial Infarction (TIMI) trial. Phase I findings. N Engl J Med. 1985;312:932-6.

16. Kawamoto A, Kawata H, Akai Y, Katsuyama $Y$, Takase E, Sasaki $Y$, Tsujimura S, Sakaguchi Y, Iwano M, Fujimoto S, Hashimoto T and Dohi K. Serum levels of VEGF and basic FGF in the subacute phase of myocardial infarction. Int J Cardiol. 1998;67:47-54.

17. Hojo Y, Ikeda U, Zhu Y, Okada M, Ueno S, Arakawa H, Fujikawa H, Katsuki T and Shimada K. Expression of vascular endothelial growth factor in patients with acute myocardial infarction. J Am Coll Cardiol. 2000;35:968-73.

18. Banai S, Jaklitsch MT, Shou M, Lazarous DF, Scheinowitz M, Biro S, Epstein SE and Unger EF. Angiogenic-induced enhancement of collateral blood flow to ischemic myocardium by vascular endothelial growth factor in dogs. Circulation. 1994;89:2183-9. 19. Pearlman JD, Hibberd MG, Chuang ML, Harada K, Lopez JJ, Gladstone SR, Friedman M, Sellke FW and Simons M. Magnetic resonance mapping demonstrates benefits of VEGFinduced myocardial angiogenesis. Nat Med. 1995;1:1085-9.

20. Kastrup J, Jorgensen E, Ruck A, Tagil K, Glogar D, Ruzyllo W, Botker HE, Dudek D, Drvota V, Hesse B, Thuesen L, Blomberg P, Gyongyosi M, Sylven C and Euroinject One G. Direct intramyocardial plasmid vascular endothelial growth factor-A165 gene therapy in patients with stable severe angina pectoris A randomized double-blind placebo-controlled study: the Euroinject One trial. J Am Coll Cardiol. 2005;45:982-8.

21. Stewart DJ, Kutryk MJ, Fitchett D, Freeman M, Camack N, Su Y, Della Siega A, Bilodeau L, Burton JR, Proulx G, Radhakrishnan S and Investigators NT. VEGF gene therapy fails to improve perfusion of ischemic myocardium in patients with advanced coronary disease: results of the NORTHERN trial. Mol Ther. 2009;17:1109-15.

22. Dvorak HF. Discovery of vascular permeability factor (VPF). Exp Cell Res. 2006;312:522-6.

23. Weis $S$, Shintani $S$, Weber A, Kirchmair R, Wood M, Cravens A, McSharry H, Iwakura A, Yoon YS, Himes N, Burstein D, Doukas J, Soll R, Losordo D and Cheresh D. Src blockade stabilizes a Flk/cadherin complex, reducing edema and tissue injury following myocardial infarction. J Clin Invest. 2004;113:885-94.

24. Weis SM and Cheresh DA. Pathophysiological consequences of VEGF-induced vascular permeability. Nature. 2005;437:497-504.

25. Galaup A, Gomez E, Souktani R, Durand M, Cazes A, Monnot C, Teillon J, Le Jan S, Bouleti C, Briois G, Philippe J, Pons S, Martin V, Assaly R, Bonnin P, Ratajczak P, Janin A, Thurston G, Valenzuela DM, Murphy AJ, Yancopoulos GD, Tissier R, Berdeaux A, Ghaleh B and Germain S. Protection against myocardial infarction and no-reflow through preservation of vascular integrity by angiopoietin-like 4. Circulation. 2012;125:140-9.

26. Bouleti C, Mathivet T, Coqueran B, Serfaty JM, Lesage M, Berland E, ArdidieRobouant C, Kauffenstein G, Henrion D, Lapergue B, Mazighi M, Duyckaerts C, Thurston G, Valenzuela DM, Murphy AJ, Yancopoulos GD, Monnot C, Margaill I and Germain S. Protective effects of angiopoietin-like 4 on cerebrovascular and functional damages in ischaemic stroke. Eur Heart J. 2013;34:3657-68.

27. van Bruggen $\mathrm{N}$, Thibodeaux H, Palmer JT, Lee WP, Fu L, Cairns B, Tumas D, Gerlai R, Williams SP, van Lookeren Campagne $\mathrm{M}$ and Ferrara N. VEGF antagonism reduces edema formation and tissue damage after ischemia/reperfusion injury in the mouse brain. J Clin Invest. 1999;104:1613-20. 
28. Kodama Y, Kitta Y, Nakamura T, Takano H, Umetani K, Fujioka D, Saito Y, Kawabata K, Obata JE, Mende A, Kobayashi T and Kugiyama K. Atorvastatin increases plasma soluble Fmslike tyrosine kinase- 1 and decreases vascular endothelial growth factor and placental growth factor in association with improvement of ventricular function in acute myocardial infarction. J Am Coll Cardiol. 2006;48:43-50.

29. Funaro S, La Torre G, Madonna M, Galiuto L, Scara A, Labbadia A, Canali E, Mattatelli A, Fedele F, Alessandrini F, Crea F, Agati L and Investigators A. Incidence, determinants, and prognostic value of reverse left ventricular remodelling after primary percutaneous coronary intervention: results of the Acute Myocardial Infarction Contrast Imaging (AMICI)

multicenter study. Eur Heart J. 2009;30:566-75.

30. Bodi V, Monmeneu JV, Ortiz-Perez JT, Lopez-Lereu MP, Bonanad C, Husser O, Minana G, Gomez C, Nunez J, Forteza MJ, Hervas A, de Dios E, Moratal D, Bosch X and Chorro FJ. Prediction of Reverse Remodeling at Cardiac MR Imaging Soon after First ST-SegmentElevation Myocardial Infarction: Results of a Large Prospective Registry. Radiology. 2016;278:54-63. 


\title{
FIGURE CAPTIONS
}

\author{
Figure 1: Flow chart
}

Figure 2: Myocardial infarction characteristics according to the presence or absence of microvascular obstruction in patients with post-PCI TIMI flow= 3 .

A. Infarct size; B. number of akinetic segments; C. left ventricular ejection fraction (LVEF).

Figure 3: Myocardial infarction characteristics evolution in patients with post-PCI TIMI flow= 3.

A. Indexed left ventricular end-diastolic diameter (LVEDi) at month 6; B. Indexed left ventricular end-diastolic diameter (LVEDi) evolution in patients with microvascular obstruction (MVO); C. Indexed left ventricular end-diastolic diameter (LVEDi) evolution in patients without MVO; D. Remodelling index in patient with and without MVO; E. Left ventricular ejection fraction (LVEF) in patient with and without MVO. 


\section{TABLES}

Table 1: Characteristics of patients according to the presence or absence of microvascular obstruction

\begin{tabular}{|c|c|c|c|c|}
\hline Variables & $\begin{array}{l}\text { All patients } \\
\quad(n=147)\end{array}$ & $\begin{array}{l}\text { No MVO } \\
(n=82)\end{array}$ & $\begin{array}{l}\text { MVO } \\
(n=65)\end{array}$ & $\mathbf{P}$ \\
\hline \multicolumn{5}{|l|}{ Clinical variables } \\
\hline Age (years) & $57.5 \pm 10.1$ & $57.1 \pm 9.8$ & $58.0 \pm 10.6$ & 0.59 \\
\hline Male gender & $124(84)$ & $68(83)$ & $56(86)$ & 0.65 \\
\hline Height $(\mathrm{cm})$ & $172 \pm 8$ & $171 \pm 8$ & $172 \pm 9$ & 0.94 \\
\hline Weight (kg) & $77 \pm 14$ & $77 \pm 15$ & $76 \pm 13$ & 0.57 \\
\hline Body mass index $\left(\mathrm{kg} / \mathrm{m}^{2}\right)$ & $26 \pm 4$ & $26.2 \pm 4.4$ & $25.8 \pm 3.9$ & 0.58 \\
\hline Systolic BP (mmHg) & $138 \pm 27$ & $134 \pm 28$ & $142 \pm 26$ & 0.11 \\
\hline Diastolic BP (mmHg) & $87 \pm 19$ & $85 \pm 19$ & $89 \pm 19$ & 0.25 \\
\hline Heart rate (bpm) & $81 \pm 19$ & $81 \pm 20$ & $80 \pm 19$ & 0.93 \\
\hline Active smoking & $82(56)$ & $50(61)$ & $32(49)$ & 0.46 \\
\hline Hypertension & $42(28)$ & $17(21)$ & $25(39)$ & 0.03 \\
\hline Dyslipidemia & $72(49)$ & $45(55)$ & $27(42)$ & 0.14 \\
\hline Diabetes & $27(18)$ & $15(18)$ & $12(19)$ & 1 \\
\hline Family history of CAD & $40(27)$ & $23(30)$ & $17(27)$ & 0.85 \\
\hline \multicolumn{5}{|c|}{ Pretreatment (at admission) } \\
\hline Beta-blockers & $13(9)$ & $8(10)$ & $5(8)$ & 0.47 \\
\hline ACEi or AT2RA & $17(12)$ & $7(9)$ & $10(15)$ & 0.21 \\
\hline
\end{tabular}




\begin{tabular}{|c|c|c|c|c|}
\hline $\begin{array}{l}\text { Statin } \\
\text { Coronary artery angiography }\end{array}$ & $15(10)$ & $11(13)$ & $4(6)$ & 0.18 \\
\hline Time from pain onset (hour) & $4.9 \pm 4.7$ & $4.8 \pm 5.0$ & $5.1 \pm 4.3$ & 0.67 \\
\hline LAD as culprit artery & $94(64)$ & $53(65)$ & $41(63)$ & 0.86 \\
\hline TIMI flow <3 after angioplasty & $17(12)$ & $9(11)$ & $8(13)$ & 0.66 \\
\hline Biological data & & & & \\
\hline T Troponin peak $(\mu \mathrm{g} / \mathrm{L})$ & $74(16-153)$ & $59(18-107)$ & $140(62-234)$ & 0.002 \\
\hline Hemoglobin (g/dL) & $13.3 \pm 1.5$ & $13.3 \pm 1.6$ & $13.2 \pm 1.4$ & 0.50 \\
\hline Creatinin (mg/L) & $9.9 \pm 3.7$ & $9.7 \pm 4.4$ & $10.3 \pm 2.49$ & 0.40 \\
\hline C Reactive Protein (mg/L) & $12(5-32)$ & $11(4-25)$ & $15(6-45)$ & 0.04 \\
\hline VEGF-A (pg/mL) & $217 \pm 168$ & $191 \pm 119$ & $250 \pm 211$ & 0.03 \\
\hline
\end{tabular}




\section{Figure 1}

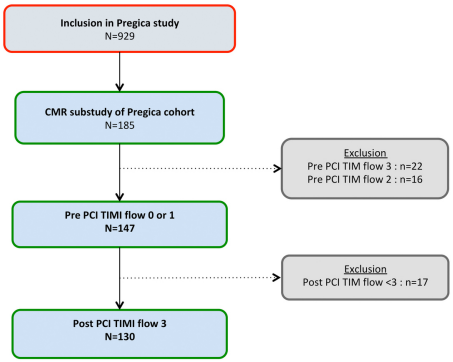




\section{Figure 2}

A

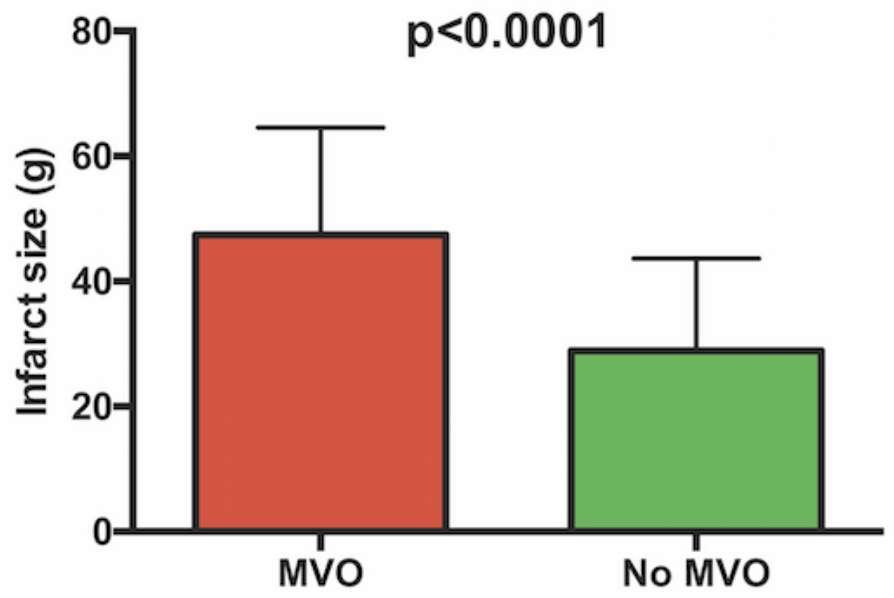

B

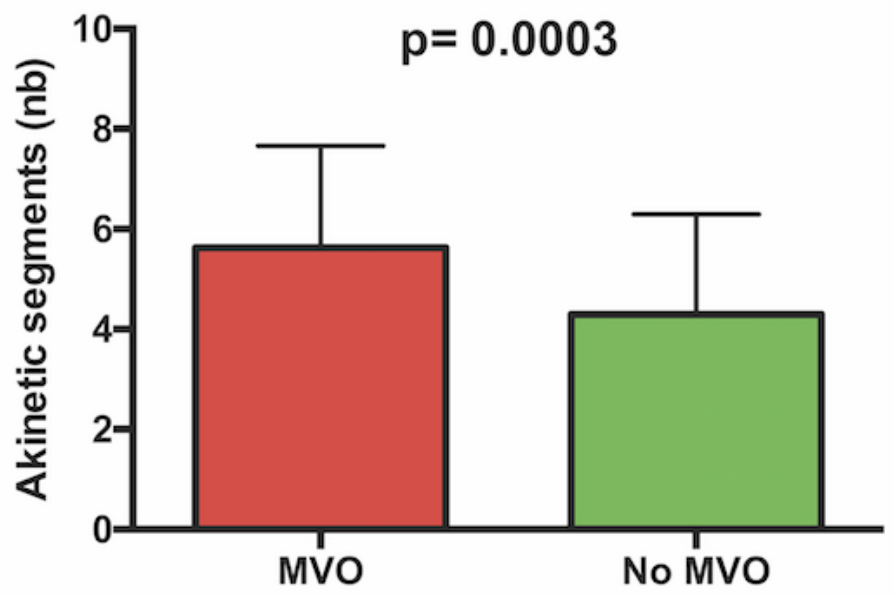

C

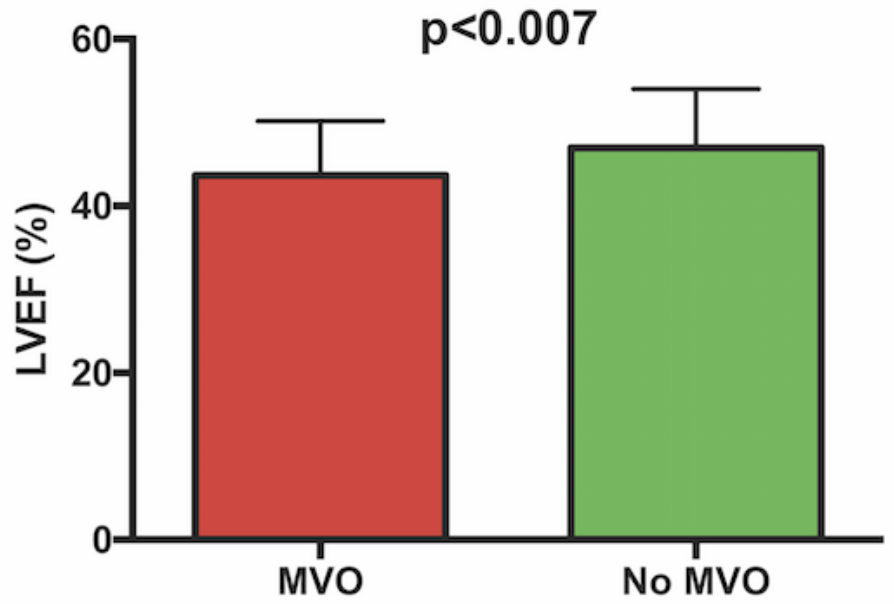




\section{Figure 3}
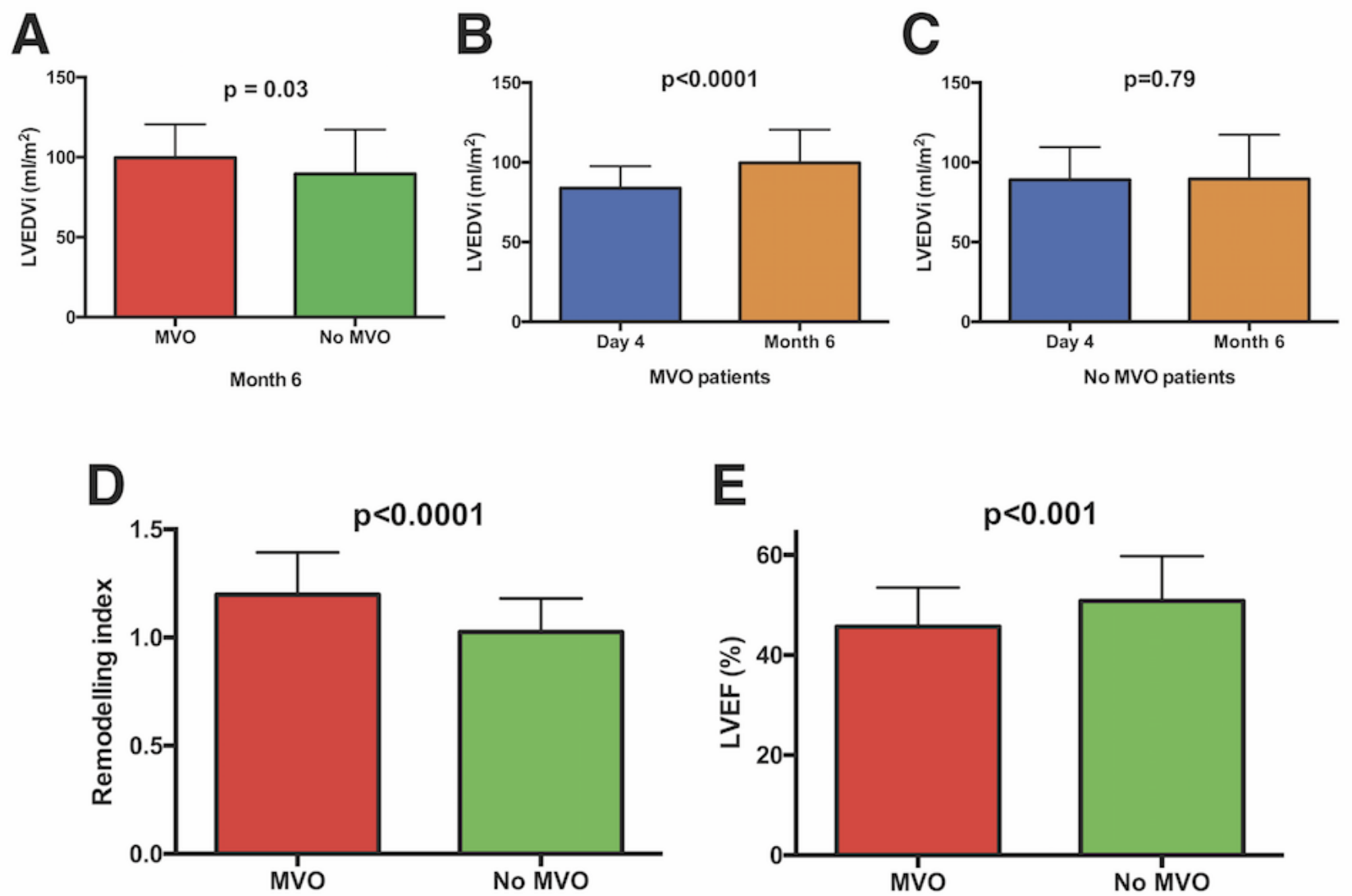

Month 6 